\title{
Observations of fine particulate nitrated phenols in four sites in northern China: concentrations, source apportionment, and secondary formation
}

Liwei Wang et al.

Correspondence to: Xinfeng Wang (xinfengwang@sdu.edu.cn)

The copyright of individual parts of the supplement might differ from the CC BY 4.0 License. 


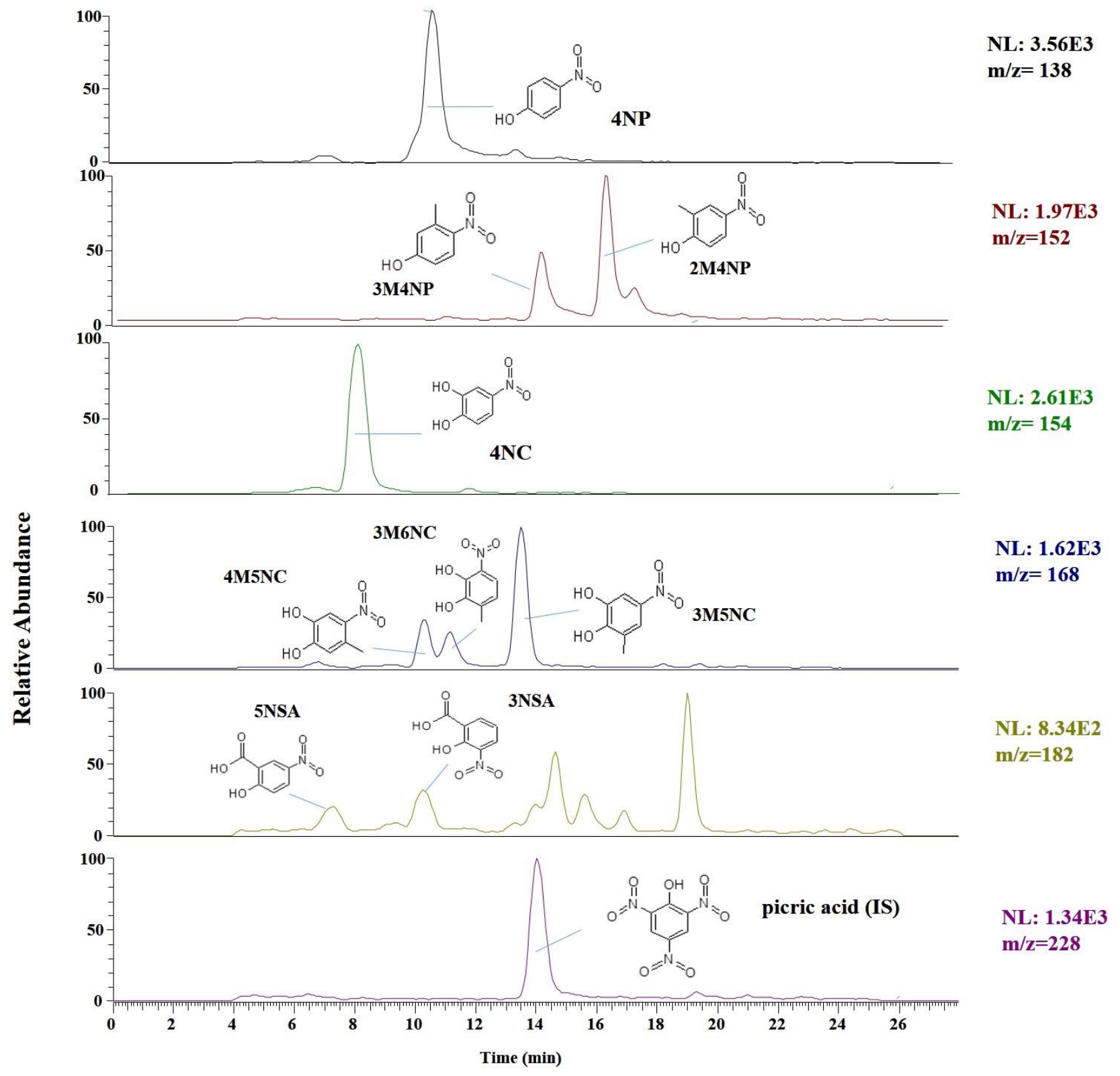

Figure S1. Extracted ion chromatogram spectra for the mass-to-charge ratios of 138, 152, 154, 168, 182, and 228 amu obtained from ambient $\mathbf{P M}_{2.5}$ sample and the identified nine nitrated phenols. 